\title{
Chagasen gaixotasuna Europan, endemikoa ez izan arren kontuan hartzekoa
}

\author{
(Chagas disease in Europe: Not endemic but worthy of consideration)
}

Gorka Gomez, Felix Olasagasti*

Biokimika eta Biologia Molekularra Saila, UPV/EHU

\begin{abstract}
LABURPENA: Chagasen gaixotasuna, tripanosomiasi amerikarra izenez ere ezagutzen dena, Carlos Chagas mediku brasildarrak 1909. urtean aurkitu zuen eritasun tropikala da. Intsektu bidez transmititzen da eta morbimortalitate-tasa altua du. Infekzioa endemikoa da Latinoamerikan, batez ere landa-ingurunean. Azken 40 urteetan, mundu-mailako osasun-arazo bilakatu da Latinoamerikatik Europa, Estatu Batuak, Kanada eta Japoniara izan diren migrazio-fluxuen ondorioz. Lan honetan, hain zuzen ere, gaixotasun honek Europan dituen ezaugarriak eta haren prebentziorako eta kontrolerako dauden neurrien berrikuspena aurkezten dugu. Europa bezalako eremu ez-endemikoetan parasitoa transmititzeko moduak sortzetiko transmisioa (amak umekiari), organoen transplantea eta odol-transfusioa izan daitezke. Europan, eskualde endemikoetako etorkin gehienak Espainiako Erresuma, Italia, Frantziako Errepublika, Erresuma Batua eta Suitzan biltzen dira. Europan egin diren seroprebalentziaren ikerketa konbinatuek $\% 4,2$ inguruko prebalentzia orokortua adierazten dute, eta prebalentzia altuena $(\% 18,1)$ jaioterria Bolivian duten banakoei dagokie. Hala eta guztiz ere, Europako herrialde gehienetan gaixotasuna ez da kontuan hartzen eta honen adierazgarri dira detekzio-programen gabezia eta diagnosia eta tratamendua izateko aukera eskasia. Etorkin latinoamerikar gehien dituzten Europako herrialdeek beren legedia aldatu eta jokaera-protokolo desberdinak garatu dituzte; baina, hala ere, neurri hauek ez dira nahikoak, ez baitute bermatzen etorkizunean transmisio kasurik ez izatea. Azkenik, ezaugarri epidemiologikoei dagokienez, gaixo gehienak adin ertaineko emakumeak direla ikusi da. Beraz, populazioa gaztea izateak arazo larriak ekar ditzake osasun-sistemarentzat, hainbat ikerketatan paziente asintomatikoen ehuneko oso altua behatu delako. Gaixo horietako batzuk kalte organikoa dagoen fasera igaroko dira eta aldi horretan tratamendua ez da batere eraginkorra. Hori dela eta, kasuen detekzio goiztiarra ezinbestekoa da osasun-sistemaren etorkizuneko arazoak saihesteko.
\end{abstract}

HITZ GAKOAK: Chagasen gaixotasuna, Trypanosoma cruzi, endemia, Europa, pandemia, osasun publikoa.

ABSTRACT: Chagas disease, also known as American trypanosomiasis, is a chronic, systemic, parasitic infection caused by the protozoan Trypanosoma cruzi. The Brazilian physician Carlos Chagas discovered it in 1909 and it is endemic to Latin America, especially to its rural areas. In the last 40 years, it has become a global health problem due to migration flows from Latin America to Europe, the United States, Canada and Japan. In this paper, we review the traits of this disease in Europe and the measures to prevent and control it. In non-endemic areas such as Europe, the routes for transmission of the parasite can be congenital (from the mother to the fetus), organ transplants and blood transfusions. In Europe, most immigrants from endemic areas are in Spain, Italy, France, the United Kingdom and Switzerland. The combined seroprevalence studies carried out in Europe show a general prevalence of $4.2 \%$ and the highest prevalence corresponds to those born in Bolivia (18.1\%). Nevertheless, most European countries disregard the disease, as evidenced by the lack of detection programs and scarce adequate diagnosis and treatment options. European countries with most Latin American immigrants have changed their legislation and developed different protocols for action; but these measures are insufficient because they do not prevent future transmission cases. Finally, regarding epidemiology, most patients are asymptomatic middle-aged women and some of them will develop the phase characterized with organic damage, when treatment is not effective. Therefore, early detection is essential to avoid future problems of the health systems.

KEYWORDS: Chagas disease, Trypanosoma cruzi, endemic, Europe, pandemic, public health.

* Harremanetan jartzeko / Corresponding author: Felix Olasagasti, Biokimika eta Biologia Molekularra Saila,UPV/EHU, Farmazia Fakultatea, Unibertsitateko ibilbidea, 7 (01006, Vitoria-Gasteiz), Araba. - felix.olasagasti@ehu.eus - https://orcid. org/0000-0002-2714-3568.

Nola aipatu / How to cite: Gomez, Gorka; Olasagasti, Felix (2019). «Chagasen gaixotasuna Europan, endemikoa ez izan arren kontuan hartzekoaw; Ekaia, 36, 2019, 311-330. (https://doi.org/10.1387/ekaia.20704).

Jasoa: 23 martxoa, 2019; Onartua: 31 uztaila, 2019.

ISSN 0214-9001 - eISSN 2444-3255 / (c) 2019 UPV/EHU

(c) (1) (2) Obra hau Creative Commons Atribución 4.0 Internacional-en

BY NC SA lizentziapean dago 


\section{SARRERA}

Osasunaren Mundu Erakundeak (OME) aintzat hartzen ez diren gaixotasun tropikal izendatu ditu gune txiro, bero eta hezeetan hedatzen diren 13 gaixotasun. Munduko beste hainbat tokitan bizi kalitatea eta garbitasuna hobetu ahala desagertu diren gaixotasun hauen artean kokatzen da Chagasen gaixotasuna eta Latinoamerikako herrialde askotan arazo ekonomiko eta sozial nabarmena eragiten du oraindik ere. Gaitz hau, tripanosomiasi amerikarra izenez ere ezagutua, Trypanosoma cruzi protozoo flagelodunak eragiten du, eta Carlos Chagas (1879-1934) mediku brasildarrak aurkitu zuen 1909. urtean. Eritasun hori parasito-infekzio kroniko eta sistemikoa da, Latinoamerikan 8 milioi pertsona ingururi eragiten diona. Populazio honen $\% 30$ eta \% 40 inguruk kardiomiopatia, digestio-megasindromea edo biak pairatuko ditu. Gaitza hainbat ornodun basatiri eragiten dion zoonosia da, triatomino deituriko intsektuen bitartez (hala nola Triatoma infestans, Rhodnius prolixus eta Triatoma dimidiata) gizakira transmititzen dena [1]. Chagasen gaixotasuna endemikoa da Amerikako 21 herrialdetan eta Estatu Batuetako hegoaldetik Argentinako Patagoniara zabaltzen da [2, 3]. 70 milioi pertsona baino gehiago daude eritasun hau pairatzeko arriskuan [2]. Azkeneko bi hamarkadetan ahalegin handia egin da herrialde endemikoetan gaixotasunaren intzidentzia murrizteko, baina Latinoamerikaren eta Europaren, Estatu Batuen, Australiaren eta Japoniaren arteko populazio trukeak azken herrialde hauetan $T$. cruzi-ren detekzio handiagoa eragin du. Eremu ez-endemikoetan, parasitoa era bertikalean transmiti daiteke (sortzetiko transmisioa amak umekiari), baita kutsatutako organo-emailearen eta odolaren bitartez ere [4]. Lan honen helburua Chagasen gaixotasuna Europan kontrolatzea garrantzitsua dela erakustea da.

\subsection{Faseak eta bilakaera klinikoa}

Chagasen gaixotasunak aldi akutua eta aldi kronikoa ditu. Aldi akututzat jotzen da infekzioa sortzen denetik mikroskopio bidez detektatzen den parasitemia negatiboa den arteko aldia. Klinika infekzioa gertatu eta 7-10 egunera hasten da, eta eskuarki sintoma arin eta ez-espezifikoak izaten dira; gripe baten ezaugarri klinikoak diruditenak [5]. Aldi honen ezaugarria, lehen aipatu bezala, mikroskopio bidez detektatzen den parasitemia da [6]. Gaixo gehienetan, transmisioaren mekanismoa edonolakoa dela ere, Chagasen aldi akutua asintomatiko izaten da, parasitoaren karga nahiko txikia izatearen ondorio. Sintomak agertzen direnean, honakoak izaten dira: luzaroko sukarra, ondoeza, gibelaren, barearen eta linfa-gongoilen handitzea, larruazalpeko edema (lokala edo orokortua) eta, bektore bidezko transmisioaren kasuan, $T$. cruzi-ren sarrera nondik gertatu den seinalea azalean (txagoma) edo begiko ehun-mukosan (Romaña zeinua, non betazalen hantura ikusiko den) [1]. Infekzio akutu gehienak ez dira inoiz hautema- 
Chagasen gaixotasuna Europan, endemikoa ez izan arren kontuan hartzekoa

ten. Infekzio horien \% 1ean baino gutxiagotan, aldi akutua larria eta potentzialki hilgarria izaten da meningoentzefalitisa edo/eta miokarditisaren ondorioz. Aldi akutua gainditzen duten pertsonetan, zelula bidezko erantzun immuneak parasitoaren erreplikazioa kontrolatzen du, sintomak berez hertzen dira, eta begien bistako parasitemia 4-8 astetan desagertzen da [6].

Ondoren, pazienteak aldi kronikora igarotzen dira. Gaixo gehienak (\% 70-\% 80) sintomarik gabe egoten dira bizitza osoan zehar. Aldi hau «gaixotasun kronikoaren forma indeterminatu» izenez ezagutzen da; klinikoki isila. Hala ere, kutsatutako pertsonen \% 20-\% 30 inguruk geroago forma determinatua garatuko du (gaixotasun kroniko sintomatikoa); eskuarki hasierako infekziotik 10-30 urtera. Forma honek bihotz-asaldurak, digestio-asaldurak (megaesofago eta megakolon) edo asaldura kardiodigestiboak ditu ezaugarri $[6,7]$. Chagasen gaixotasunaren berraktibatzea immunologikoki konprometitzen diren infekzio kronikodun gaixoetan ez ezik, GIBarekin kutsatuta daudenetan edo sendagai immunokentzaileak hartzen dituzten horietan ere gerta daiteke [8].

\subsection{Etiologia}

\subsubsection{T. cruzi-ren bizi-zikloa}

Aldi akutuan zehar, gizakiaren nukleodun zelula mota guztiak dira infekzioaren itu nagusi. Erantzun immunearen garapenarekin batera, parasitemia kontzentrazio azpipatente batera murrizten da eta ehunetako parasito kopurua era nabarmenean jaisten da; horrek aldi akutuaren amaiera adierazten du. Hala ere, parasitoa guztiz ezabatzen ez denez, ehun jakinetako infekzioak (gihar- edo heste-gongoiletan agertzen dena), denbora mugagabez iraungo du ostalariaren bizitzan zehar [1].

\subsubsection{Transmisio-bideak}

\subsubsection{Bektore bidezko transmisioa}

Zona endemikoetan, parasitoaren transmisio-bide nagusia bektore bidezkoa da. Chagasen gaixotasuna etxebizitzetan aurkitzen diren intsektu triatomino hematofagoen bidez (zimitz izenez ezagutzen diren etxe-bektoreak) transmititzen da. Orokorrean, transmisioa gauez gertatzen da, zimitzak aktiboago daudenean. Momentu horretan lo dauden pertsonen odola hartzen dute. Ziztadaren jarraian, bektoreak, ostalariaren larruazalean edo mukosetan, bere gorozkiak uzten ditu, parasitoaren forma tripomastigote metazikliko infektiboa daramatenak. Senezko igurztearen ondorioz, forma horiek larruazala zeharkatzen dute [1,9]. Europan, beste zona ez-endemikoetan bezala, bektorerik ez dagoenez, transmisio mota hori ez da bideragarria [10]. 


\subsubsection{Sortzetiko transmisioa (bertikala)}

Haurdunaldian gertatzen den T. cruzi-ren bidezko infekzioaren fisiopatologia ez dago guztiz argi, baina transmisio mota hau zona endemikoetatik kanpo ere gerta daiteke [11]. Kasu bat sortzetikoa dela jotzeko, honako irizpide hauetatik bi bete behar dira, eta lehenengoa betetzea ezinbestekoa da [12]:

- Umearen amak T. cruzi-rentzako serologia positiboa izan behar du, bi metodo desberdinen bidez determinatua. Modu honetan, aurretiko odol-transfusioa edo bektore bidezko transmisioa baztertu daitezke.

- Parasitoak (zuzeneko edo zeharkako tekniken bidez) jaioberriaren odol-korrontean identifikatu behar dira, jaiotzaren momentuan edo jarraipenaren lehenengo hilabeteetan zehar.

- Anti-T. cruzi (IgG) antigorputzak aurkitu behar dira umean, jaio eta hurrengo 9 hilabeteetan. Eskuarki, momentu honetan, amaren bidez era pasiboan transmititutako antigorputzak desagertu egiten dira.

\subsubsection{Odol-transfusioa}

Kutsatutako emaile baten odol-unitate bateko transfusioaren ondorioz Chagasen gaixotasuna izateko arriskua \% 10-\% 20 baino txikiagoa da. Hainbat faktoreren araberakoa da: emailearen odolean dagoen parasito-kontzentrazioa, transfunditutako odolaren osaketa eta, seguruenik, parasitoaren anduia. Arriskua handiagoa da transfusioa plaketena denean, odoleko beste osagai batzuena denean baino [13, 14].

\subsubsection{Organoen transplantea}

Transplantatutako gaixoen $T$. cruzi-ren bidezko infekziorik gehienak Latinoamerikan deskribatu dira. Organoen eskasiaren eta gaixotasunaren prebalentziaren ondorioz, emaile baten serologia positiboak ez du transplantea kontraindikatzen (bihotzeko transplanteen kasuan izan ezik). Diagnostiko goiztiarra eta terapia zehatz baten hastea ezinbestekoak dira konplikazioak saihesteko. Bihotzeko transplanteen kasuan, arestian aipatu bezala, infekzio kronikoa duen gaixo baten bihotzaren erabilera erabateko kontraindikazioa da, immunoezabatze-aldian miokarditis chagasikoa garatzeko arriskua dela eta [15].

\subsubsection{Aho bidezkoa}

Kasu gutxi batzuetan, gaixotasuna kutsatutako elikagaien edo uraren ingestioaren ondorioz bereganatu daiteke. Orokorrean, aho bidez transmi- 
titzen den Chagasen gaixotasuna intsektua etxe-bektorea ez den eremuetan izaten diren infekzio akutuaren agerraldien erantzulea da. Kutsatutako elikagaien irenstea parasito-infestazio masiboekin erlazionatzen da. Hainbat modu daude gaitz hau aho bidez bereganatzeko; horien artean: kutsatutako ama-esnearen ingestioa, kutsatutako animalien haragi gordin edo gutxi eginarena, kutsatutako triatominoekin edo/eta hauen gorozkiekin kutsatutako elikagaiena, martsupialen uzki-guruinen jariakinekin kutsatutako elikagaiena eta triatominoen beren ingestioa [16]. Transmisio mota hori gaixotasuna transmititzen duen intsektua aurkitzen den herrialdeetan bakarrik gertatzen da [17].

\subsubsection{Laborategi-istripuak}

Laborategi kliniko edo ikerketa-laborategietan lan egiten duten pertsonek $T$. cruzi-rekin kutsatzeko arriskua dute; zehazki, parasito bideragarriak (hala nola tripomastigote infektiboak, amastigote infektiboak edo amastigote metaziklikoak) dituzten materialen maneiuaren bitartez. Baldintza askotan gertatu eta maiz oharkabekoak edo diagnostikatu gabekoak izan daitezkeenez, gerta daiteke laborategietan izaten diren kutsaduren berri ez ematea. Gainera, ez dago horien zabalkundea egiteko interesik (isilean eduki edo ukatu ere egiten dira), segurtasun-neurri desegokien edo esperientzia tekniko gabeziaren isla izan daitezkeelako [18-21]. Transmisiobide hau ez da oso ohikoa [1].

\subsection{Banaketa geografiko berria}

Tripanosomiasis amerikarra Latinoamerikako zoonosi endemikoa da, gaur egun 8-10 milioi pertsonari erasaten diena. 60 milioi pertsona bizi dira bektore bidezko transmisioz kutsatzeko arriskua dagoen eremuetan, eta gaitzak 14.000 hildako eragiten ditu urtero [22]. Herrialde endemikoetan dauden zailtasun ekonomiko eta arazo politikoen ondorioz, emigrazio nabaria gertatu da zona horietatik herrialde ez-endemiko garatuetara [23]. Modu horretan, historikoki biztanleria txiro eta landatarren gaixotasuna, Latinoamerikako hirietara ez ezik, Latinoamerikako mugatik harantz hedatu da [22, 23]. Oraindik ere Estatu Batuak dira helmuga nagusia, baina 2001 eko irailaren $11 \mathrm{ko}$ atentatuen ondorengo muga-estutzearen ondorioz, Europako latinoamerikar etorkinen kopurua bikoiztu baino gehiago egin zen. Japoniak, Australiak eta Kanadak ere latinoamerikar etorkin kopuru nabarmena jaso dute azken urteetan [22].

\subsection{Osasun-erronka berria Europan}

2008. urtean, 38 milioi etorkin baino gehiago bizi ziren Europan (horien erdiak inguru Espainiar erresuman) eta horien \% 11 latinoamerika- 
rra zen. EAEko, Nafarroako Foru Erkidegoko eta Pirinio Atlantikoen departamentuko datuak kontuan hartuz, kalkulatzen dugu Euskal Herrian 110.000tik gora direla eskualde horretako jatorria duten etorkinak [24-26]. Balio horiek ez dituzte kontuan hartzen baliozko bizileku-baimenik gabeko etorkinak (etorkin «irregular» eta nortasun-agiririk gabeak), Europatik kanpo jaiota europar herritartasuna bereganatu duten pertsonak edo atzerrian jaio eta familia europarrek adoptatu dituzten umeak. Zifra ofizialek, beraz, eskualde endemikoetako etorkinen kopurua gutxiesten dute, eta, hori dela eta, tripanosomiasi amerikarra duten gaixoen zenbatekoa ere bai [27].

Gaur egun, T. cruzi-rekin infektatutako pertsona kopuru oso txikia detektatu da Europan. Hainbat arrazoik azaltzen dute gertaera hori [4]:

- Europako osasun-profesionalik gehienek ez dute esperientziarik, edo oso eskarmentu txikia du Chagasen gaixotasunaren detekzioan edo tratamenduan [28].

- Arriskuan dauden komunitateek sarbidea oso mugatua dute detekzio-programetan parte hartzeko. Oso erakunde gutxik eskaintzen dituzte ebaluaketak, orokorrean hiri-eremu nagusietan.

- Aldi kronikoaren diagnostikoa atzeratu egiten da, kasu gehienetan gaixoak sintomarik gabe egoten baitira urte askotan zehar [1].

Europako bost herrialdetan 2005-2010. urteen bitartean egindako 18 lanen datuen arabera, Chagasen gaixotasun kronikoaren prebalentziaren balioa \% 4,2 ingurukoa da (\% 0-\% 15,9) Europan. Herrialde endemikoetako infekzio-tasak oinarri hartuta, Europan 68.000-120.000 kasu daudela kalkulatu da (Espainiako Erresuman horietatik 42.000) [29, 30].

\section{LEHEN MAILAKO KONTROL ETA PREBENTZIOA}

Azken urteetan, zenbait ekimenek, gobernuz kanpokoek zein ondoren gobernuek eurek antolatuek, osasun publikoaren arazo honi aurre egiteko estrategiak garatu dituzte. Ekimen horien helburu nagusia herrialde ez-endemikoetako transmisio-bide nagusiak kontrolatzea izan da. Hortaz, Europako herrialde batzuek transmisioa kontrolatzeko nazio- eta eskualde-mailako neurriak inplementatu dituzte. Hala ere, herrialde askok oraindik ez dute horren inguruko araudirik [31].

Europan eta gainerako eremu ez-endemikoetan bektorerik ez dagoenez, horren bidezko transmisioa ez da bideragarria; hala ere, beste transmisiobideen bitartekoa izan daiteke. Garrantzitsuena sortzetiko transmisioa da, eta, jarraian, odol-transfusioaren eta organo-transplantearen bidez gertatzen diren kasuak aurkitzen dira [22]. 
Chagasen gaixotasuna Europan, endemikoa ez izan arren kontuan hartzekoa

\subsection{Sortzetiko transmisioa}

Ez dago baheketarik Chagasen gaixotasuna endemikoa den eremuetatik datozen emakume haurdunei dagokienez, eta Europako herrialdeetan ez dago legedirik haien seme-alaben jagoletza eskatzen duenik; Espainiako Erresumako hiru autonomia-erkidegotan (Katalunia, Galizia eta Valentzia), Italiako eskualde batean (Toskana) eta Geneva hirian (Suitza) izan ezik [31, 32]. Bost leku horietan, jaio aurreko arretan zehar, beharrezkoak diren baheketa-frogen parte den T. cruzi-ren probak egin behar dira. Proba horiek ELISA (enzyme-linked immunosorbent assay) eta IFI (Indirect Immunofluorescence) teknikak izaten dituzte oinarri, eta, haurdun dauden emakumeek positibo ematen dutenean, sortzetiko Chagasen gaixotasunaren proba egiten zaie jaioberriei. T. cruzi-rekin kutsatuta badaude, goizik tratatzen dira. Proba horrek negatibo ematen badu, bederatzi hilabetez egiten zaie segimendua, gutxienez; infekzioa modu fidagarrian baztertu daitekeen arte [31].

Chagasen gaixotasunaren sortzetiko transmisio-tasak, Europan, \% 2,6 eta \% 13,8 bitartekoak dira (gehienak Espainiako Erresuman), eta batez besteko tasa \% 6 da [33-36]. Azken urteotan egindako ikerketek adierazten dute badagoela lotura estatistikoki adierazgarririk Chagasen gaixotasunaren sortzetiko transmisioaren eta haurdunaldian zehar amaren odolak duen PCR bidezko erantzun positiboaren artean [36]. Sortzetiko infekziodun jaioberriek parasitemia-maila altuak izaten dituzte, eta diagnostikoa zilbor-hestean edo aurretiazko kontzentrazio-prozedura izan duen odol periferikoan (mikrohematokrito proba) T. cruzi-ren tripomastigote mugikorrak mikroskopikoz detektatuz berresten da [37]. Sortzetiko infekzioaren detekzio goiztiarrerako PCR bidezkoa zuzeneko mikroskopia baino sentikorragoa dela dirudi, baina gaur egun OMEk ez du honen erabilera gomendatzen [38]. Emaitza parasitologiko negatiboen kasuetan edo jaiotzean baheketarik egin ez denetan infekzioa dagoela baztertzeko, ama seropositiboen haurtxoei ebaluazio serologikoa egin behar zaie 9 hilabeteko adina dutenean [32].

\subsection{Odol-transfusioaren bidezko transmisioa}

Odol-transfusioaren bidezko transmisioaren ondoriozko T. cruzi-ren infekzioaren hainbat kasu identifikatu dira Europan [39]. Nahiz eta Europar Batasuneko eta Suitzako odol-transfusioari dagokion osasun-politika aldakorra den [31], T. cruzi-rekin kutsatuta egoteko arriskua duen odolaren detekzio sistematikoa Erresuma Batuan aplikatu zen lehenengoz, 1999. urtean; ondoren, Espainiako Erresuman (2005), Frantziako Errepublikan (2009), Suedian (2009), Suitzan (2012), eta, azkenik, Belgikan (2013) inplementatu zen [31, 39-43]. Herrialde horietan, eskualde endemikoetan jaiotako emaileei, edo ama eskualde endemikoetakoa duten emaileei, edo 
eskualde endemikoetan odol-transfusioak jaso dituzten emaileei, T. cruziren infekzio-proba egin behar zaie odola eman aurretik [31].

Espainiako Erresumaren kasuan, zehazki, honako hauek dira irizpideak [44]:

- Chagasen gaixotasunaren aurrekariak dituzten pertsonek ezingo dute odola eman.

- Arriskua duten emaileetan balioetsitako proba batek T. cruzi-ren infekzioa baieztatzen badu, kasu horretan ere odola ematea debekatuta dago. Emaile arriskutsutzat jotzen dira eskualde endemikoetan jaiotako emaileak, edo ama eskualde endemikoetan jaioa duten emaileak, edo eskualde endemikoetan odol-transfusioak jaso dituzten emaileak.

- Herrialde endemikoetan egon diren bisitariak onartzen dira, are landa-eremuetan egon badira ere. Alde landatarretan hilabete batez edo gehiagoz lanean egon diren horiek badute gaixotasuna bereganatzeko arrisku posiblea; baina ez dago baztertzeko arrazoi nahikorik. Anti-T. cruzi antigopurtzen detekzio-proba batek argituko ditu zalantza guztiak. Proba, gutxienez, azken bisitatik 6 hilabetera egin behar da.

Gainerako Europar Batasuneko herrialdeek Europako Batzordearen legedia aplikatzen dute (2004/33/EC eta 2006/17/EC). Araudi honek T. cru$z i$-rekin kutsatutako pertsonak odola ematetik kanpo uzten ditu, infekzioarekin era potentzialean kontaktuan egon diren emaileekin hartu behar diren neurriak aipatu gabe [32].

Odolaren osagaiei dagokienez, parasito-karga handiena plaketen kontzentratuetan behatzen da, eta bigarren kontzentrazio altuena globulu gorrien prestakinetan $[32,45]$, baina azken hauetan filtraziozko leukomurrizketak T. cruzi-ren infekzioaren arriskua ia guztiz deuseztatzen du.

\subsection{Organoen transplantearen bidezko transmisioa}

Organo solidoen donazioa arautzen duten Europar Batasuneko legeek ez dituzte $T$. cruzi-ren bidezko infekzioa kontrolatzeko neurriak era espezifikoan azaltzen, baina Espainiako Erresumako transplante-erakundeak, Italiakoak eta Erresuma Batukoak badituzte Chagasen gaixotasunaren transmisioa kontrolatzeko gomendioak beren gidalerroetan. Ondorioz, herrialde horietako organo-emaileak beti aztertzen dira; Chagasen gaixotasunarentzako seropositibotasuna transplanterako kontraindikazioa izan ez arren [31]. Adibide moduan, infekzio-arriskua duten emaileei $T$. cruzi-ren proba egiteko gomendioa oso argia da Espainiako Erresuman: emaile positibo baten organoaren hartzaileei jarraipen zorrotza egiten zaie eta monitorizatu egiten dira, T. cruzi-ren garapena gertatzen ez dela bermatzeko [46]. 
Era berean, Erresuma Batuko Odolaren, Ehunen eta Organoen Segurtasunaren inguruko Osasun Departamentuaren Batzorde Aholkulariak (SaBTO siglak ingelesez) eta Europako Kontseiluak ere bere «Transplanterako organoen kalitate eta segurtasun gida» eta «Giza aplikaziorako ehun eta zelulen kalitate eta segurtasun gida» deitzen diren gidaliburuetan ebaluazio-, froga- eta kontraindikazio-irizpideak zehazten dituzte [31].

\section{EPIDEMIOLOGIA}

\subsection{Intzidentzia eta prebalentzia}

Aurretik esan dugunez, Europan 68.000-120.000 kasu daudela kalkulatu da [1, 27, 34] eta horietatik Boliviako etorkinek dute prebalentzia altuena $(\%$ 18,1). Jarraian, El Salvador $(\%$ 5,6), Paraguai $(\%$ 5,5), Nikaragua (\% 4,6), Honduras (\% 3,7) eta Argentinako (\% 2,2) etorkinak aurkitzen dira. Beste herrialde bateko etorkinen prebalentzia \% 1 baino txikiagoa da $[1,30,34]$.

Kutsatutako pertsona gehienak infekzioa beren jaioterrian bereganatu zuten etorkinak dira, eta fase kronikoan daude harrera-herrialdera iristen direnerako. Chagasen gaixotasuna dutenen \% 30ek errai-arazoak gara ditzakeela kontuan hartuz, Europan bizi diren 20.400-36.600 etorkin inguruk errai-konplikazioak ditu edo izango dituela kalkula daiteke. Hala ere, gaur egun, horien $\% 10$ baino gutxiago diagnostikatu dira [30, 34].

Europan gaixotasuna hartzeko aukera gutxietako bat sortzetiko transmisioa da. Hori dela-eta, 2009. urtean, ikerketa epidemiologiko bat diseinatu zen Chagasen gaixotasunaren sortzetiko transmisioaren intzidentzia determinatzeko. Behaketa-unitateak OMEren arabera gaixotasunaren 400 kasu baino gehiago izan zituzten herrialdeak izan ziren [4], hau da, Alemania, Belgika, Erresuma Batua. Espainiako Erresuma, Frantziako Errepublika, Herbehereetako Erresuma, Italia, Portugal eta Suitza [27].

Azterturiko herrialdeetan, ama eskualde endemikoetakoa zuten ia 53.000 ume jaio ziren 2009an. Horietatik, 1.347-2.521 bitarte ama T. cru$z i$-rekin kutsatuta zeuden; eta sortzetiko transmisioa 20-184 kasutan gertatu zen; beste modu batera esanda: arriskuan dauden amen 1.000 jaiotzako, zero eta hiru bitarte dira ume kutsatuak. Eskualde endemikoetakoak ziren amen jaiotzen \% 67 Espainiako Erresuman izanik, sortzetiko transmisio kasuen ia \% 90 herrialde honetan jazo zen. Beste herrialde batzuetan, urteko izan ziren sortzetiko transmisioen kasuak zero eta sei bitarte izan ziren [27]. 


\subsection{Ezaugarri klinikoen epidemiologia}

Chagasen gaixotasunaren berezko garapenean aldi akutua eta ondorengo aldi kronikoa aurkitzen dira. Azken hau aldi kroniko goiztiarrean eta aldi kroniko berantiarrean banatzen da, sortasun-denboraldiaren iraupenaren arabera (hau da, 20 urte baino gutxiago edo gehiago, hurrenez hurren). Herrialde endemikoetan, Chagasen gaixotasun akutua umeek pairatzen dute, baina kasu gehienetan ez da detektatzen, gaitzaren aurkezpen arin eta inespezifikoa edo arreta mediko eza direla eta. Sukarra, anorexia, linfadenopatia, Romaña zeinua eta hepatoesplenomegalia dira aldi akutuaren ezaugarri kliniko nagusiak [47].

Gaixotasunaren forma larriagoa infekzio akutudun gaixoen \% 1ean agertzen da, eta miokarditisa, perikarditisa edo meningoentzefalitisa ditu ezaugarri. Heriotza-arriskua \% 0,2-\% 0,5 bitartekoa da [47].

Chagasen gaixotasun akutuaren kasu gutxi batzuen berri besterik ez da eman Europan; Latinoamerikako herrialde endemikoetan egon diren bidaiariak, herrialde endemikoetako etorkinak eta Europan bertan gertatu diren kasuak (sortzetiko transmisioa, odol-transfusioa edo transplantea) dituzte oinarri [48-51]. Europan behatu diren gaixo gehienak infekzioaren aldi kroniko eta indeterminatuan daude, eta aldi kliniko horren prebalentzia \% 68-\% 72 bitarte da [52-56], eta Espainiako Erresuman egin zen ikerketa baten arabera, pazienteen \% 31,5ek anomalia elektrokardiografiko bat zuen [55].

Europan aztertu diren pazienteetan, Chagasen gaixotasunaren adierazpen kliniko digestiboak \% 9-\% 21 bitarteko prebalentzia du [52, 53, 57, 58]. Digestio-larritasuna duten gaixoen sintoma ohikoenak disfagia eta idorreria dira, espezifikoak ez diren arren $[57,58]$. Hala ere, sintoma horiek dituzten latinoamerikarrei $T$. cruzi-ren aurkako serologia-azterketa egitea ezinbestekotzat jotzen da [58]. Esofagopatia duten gaixoen asaldura arruntenak hipotentsioa eta azpiko esfinter esofagikoaren erlaxazio bukatugabea dira, eta pazienteen \% 62tan dolikokolon/dolikosigma agertzen da $[53,57,58]$.

\subsection{Kate epidemiologikoa}

T. cruzi-ren bizi-zikloa konplexua da (1. irudia). Tripomastigote ezerreplikatzaileak, odol-korrontean, eta zelula barneko amastigote erreplikatzaileak dira ostalari ugaztunetan aurkitzen diren ohiko formak. Triatomino bektorean, aldiz, epimastigote erreplikatzaileak eta tripomastigote metazikliko infektiboak aurkitzen dira [59, 60]. 


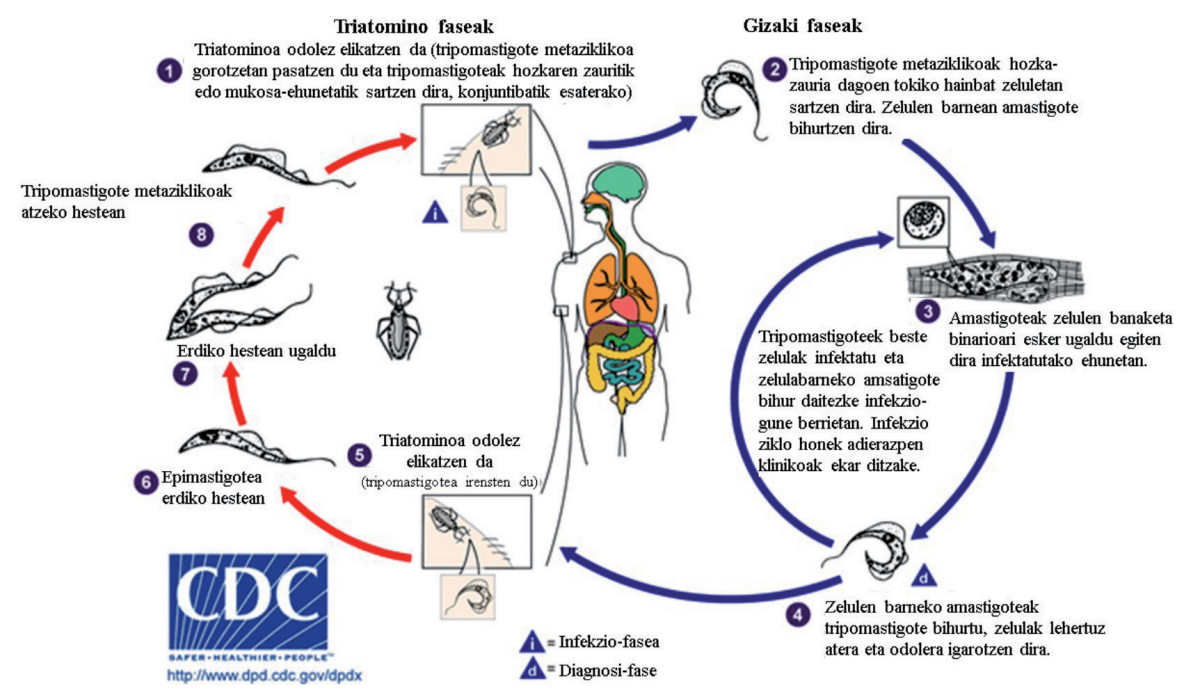

1. irudia. T. cruzi-ren bizi-zikloa. AEBko CDC (Gaixotasunen Kontrol eta Prebentziorako Zentroak) erakundearen irudia, moldatua [61].

\section{TRATAMENDU FARMAKOLOGIKOA}

Txertorik ez dagoenez [62], tratamenduaren helburua parasitoa deuseztatzea eta gaixotasunaren zeinu eta sintomak ezabatzea da [1].

\subsection{Tripanosomen aurkako tratamendua}

2005. [63] eta 2007. [64] urteetan argitaratutako gomendioen arabera, tripanosomen aurkako tratamendua hurrengo kasuetan aplikatu behar da: infekzio akutuetan, sortzetikoetan eta berraktibatuetan, infekzioa duten ume guztietan eta gaixotasun kronikodun 18 urterainoko pazienteetan [1]. Tratamendu farmakologikoa, orokorrean, Chagasen gaixotasun kardiako aurreratua (kardiomiopatia) ez duten 19 eta 50 urte bitarteko helduei eskaini behar zaie [64]. Haurdunaldian zehar, berriz, mota honetako tratamendua kontraindikatuta dago, baita gibel- edo giltzurrun-gutxiegitasun larria duten gaixoetan ere $[1,32]$. Kasu hauetaz gain, irensketaren murrizketa eragiten duen megaesofagoa edo Chagasen gaixotasun kardiako aurreratua duten pazienteei ez zaie tripanosomen aurkako tratamendua eskaini behar [1].

Chagasen gaixotasunaren tratamendu etiologikoa duela 40 urte baino gehiago garatu ziren benznidazol eta nifurtimox medikamentuetan oinarritzen da [5, 65]. Ez bata, ez bestea ez dago Europan erregistratua, OMEk behar-beharrezko medikamentutzat jotzen dituen arren $[47,66]$. Nifurti- 
moxa zuzenean eskura daiteke OMEren bitartez; benznidazola, berriz, medikamentu hori erabiltzen den herrialde latinoamerikarretatik inportatu behar da [32].

Erantzun terapeutikoa eremu geografikoaren eta gaixotasunaren fasearen araberakoa da batik bat. Eritasunaren aldi goiztiarrean bi medikamentuek sendatze-tasa onargarria dute, pazienteen \% 65-\% 80 bitartekoa; eta era goiztiarrean tratatzen diren sortzetiko transmisioaren kasuetan, sendatze-tasa \% 95 ingurukoa izaten da [67, 68]. Gaixotasunaren aldi kronikoan, berriz, \% 15-\% 40 bitarteko sendatze-tasa lortzen da [69].

\subsection{Bihotzeko arazoen tratamendua}

Gaixotasunaren aldi kronikoaren konplikazio larriena Chagasen kardiomiopatia da eta pazienteen heriotza gehienak eragiten ditu, bihotz-gutxiegitasuna, tronboenbolismoa eta berehalako heriotza kardiakoa direla eta. Denbora askoan zehar, gertakari autoimmuneak hartzen ziren Chagasen gaixotasunean behatzen den organoetako kaltearen eragiletzat; hala ere, azkenaldiko proba kliniko eta esperimentalek baieztatu dute funtsa dagoela parasitoak ostalarian duen iraunkortasunak eragindako hanturazko erantzunean $[70,71]$. Chagasen kardiomiopatiaren diagnosia datu klinikoetan, erradiografikoetan (hau da, indize kardiotorazikoa $>0,5$; toraxeko erradiografian neurtutakoaren arabera) eta anomalia elektrokardiografikoetan oinarritzen da. Chagasen serologia positibodun paziente guztien hasierako tratamendua gorputz-miaketa xeheak, 12 deribazioko elektrokardiogramak eta bihotzeko eritasuna baztertzeko toraxeko erradiografiak osatzen dute [72-75].

Ausazko entsegu kontrolatu baten gabezia dela eta, Chagasen bihotzgutxiegitasuna duten gaixoen tratamendua bestelako jatorriak dituen bihotz-gutxiegitasunaren tratamendurako garatu diren gidalerroetatik estrapolatu da [76]. Hala ere, Chagasen gaixotasun kardiakoaren fisiopatologiak garrantzi kliniko eta inplikazio terapeutikoak izan ditzaketen berezitasun batzuk ditu. Adibidez, gaixotasunaren fase aurreratuan diuretikoen dosiaren igoera justifikatuta dago, biriketako kongestioaren zeinuen gaineko seinale sistemiko kongestiboen gailentasuna dela eta. Chagasen gaixotasun kardiakoa duten gaixoek kondukzioaren asaldura nabariak ere izaten dituzte, eta bai bradikardia sintomatikoa pairatzeko joera ere. Azken arazo horrek okerrera egiten du digoxina, amiodarona eta, bereziki, beta-blokeatzaileak erabiliz gero [77]

Kardiomioplastia dinamikoari, ezkerreko bentrikulektomia partzialari eta gisako prozedura aringarriei dagokienez, prozedura horiek guztiz kontraindikatuta daude, behatu diren emaitzek ez baitute arrakastarik izan. Bihotz-transplantea alternatiba izan daiteke fase terminalean dauden paziente batzuentzat. Azkenaldian egin diren aurkikuntza batzuen arabera, 
Chagasen gaixotasun kardiakoa duten paziente transplantatuen biziraupena hobea da beste bihotz-gaixotasunen bat dela-eta transplantatuak izan diren gaixoena baino [78]. Hala ere, gertakari tronboenbolikoen intzidentzia altua dela eta, aho bidezko antikoagulatzaileak fibrilazio aurikularra, aurretiko enbolia eta aneurisma apikala dituzten pazienteei administratzea gomendatzen da [1].

\subsection{Urdail-hesteetako arazoen tratamendua}

Megaesofagoaren tratamenduaren helburu nagusia sintomen arintzea da, hestegorriko beheko esfinterraren bidezko elikagaien eta likidoen igarotzea erraztuz. Megaesofago ez aurreratua tratatzeko aukera aproposena funduplikatura laparoskopiko bidezko Hellerren miotomia da, behin betikoa izaten da eta. Kasu aurreratuetan, emaitza desberdinak izan dituzten hestegorriko erresekziorako teknika desberdinak erabili dira [79].

\section{ONDORIOAK}

Europako gaur egungo egoera aztertuz, ezin da baztertu gune endemikoetatik kanpoko hiru transmisio-bide arruntak (sortzetikoa, odol-transfusioa eta organoen transplantea) gerta daitezkeela. Hori dela eta, eritasuna garaiz detektatzeko garrantzitsua da lehen mailako arretako osasun profesionalak kontzientziatzea. Bestalde, medikuntza tropikalean adituak diren zentroekin elkarlanean aritzea oso lagungarria litzateke, horiek baitaude kontaktuan arriskuan dauden paziente gehienekin.

Nahiz eta populazioaren heterogeneotasuna nabaria den, honakoa da Chagasen eritasuna pairatzen duen gaixoaren profila: infekzioaren fase indeterminatuan aurkitzen den emakume boliviar gaztea. Gaixotasunaren bilakaera kontuan hartuz, gaur egunean Chagasen eritasuna pairatzen dutenetako batzuk urte batzuk barru bihotz-kaltea izango duten pazienteak izango dira. Infekzioa garaiz detektatzen bada, ordea, saihetsi egin daiteke egoera hori, gaur egungo tratamendua ez baita eraginkorra errai-kaltea dagoen aldi kronikoan. Aldi berean, zama astuna ekidingo genioke osasun sistema publikoari. Gainera, adin ugalkorrean daudenez, sortzetiko transmisioa ekiditeko protokoloaren berebiziko premia dago.

Gaur egun, T. cruzi-ren deuseztatzea lor daiteke eskuragarri dauden medikamentuak bitarteko direla (benznidazol eta nifurtimox), baina profil zehatz bat duten gaixoetan bakarrik dira eraginkorrak. Hori dela eta, Chagasen gaixotasuna kontrolatzeko orduan, ezinbestekoa da infekzio kronikodun gaixo helduentzako parasitoen kontrako tratamendu egokia garatzea eta osasun-zerbitzuek zein gaixotasunen kontrol-programek behar adina baliabide izatea. 
Gaixotasunak aurrera egin ahala tratamenduaren eraginkortasuna nabarmen murrizten denez, prebentzioan eta lehen mailako arretan oinarritzen den legedi europar komunak garatzea ezinbestekoa da edozein motatako transmisioak ekiditeko. Gauza batzuk egin diren arren (eredutzat har daitekeen Kataluniako jagoletza-sistema, esaterako), oraindik asko dago egiteko.

\section{BIBLIOGRAFIA}

[1] RASSI A. JR, RASSI A. eta MARIN-NETO J.A. 2010. «Chagas disease». Lancet, 375, 1388-1402.

[2] MESSENGER L.A., MILES M.A. eta BERN C. 2015. «Between a bug and a hard place: Trypanosoma cruzi genetic diversity and the clinical outcomes of Chagas disease». Expert Review of Anti-Infective Therapy, 13, 995-1029.

[3] RODRIGUEZ I.G. eta LOAIZA J.R. 2017. «American trypanosomiasis, or Chagas disease, in Panama: a chronological synopsis of ecological and epidemiological research». Parasites \& Vectors, 10.

[4] World Health Organization (WHO). Control and prevention of Chagas disease in Europe. Report of a WHO Informal Consultation (jointly organized by WHO headquarters and the WHO Regional Office for Europe) Geneva, Switzerland, 17-18 December 2009. Final report. Geneva: WHO; 2010. Report No.: WHO/HTM/NTD/IDM/2010.1.

[5] MOLINA I., SALVADOR F. eta SANCHEZ-MONTALVA A. 2016. «Update Chagas disease». Enfermedades Infecciosas y Microbiología Clínica, 34, 132-138.

[6] BERN C. 2015. «Chagas' Disease». New England Journal of Medicine, 373, 456-466.

[7] COURA J.R. eta BORGES-PEREIRA J. 2010. «Chagas disease: 100 years after its discovery. A systemic review». Acta Tropica, 115, 5-13.

[8] BRAZ L.M.A., NETO V.A. eta OKAY T.S. 2008. «Reactivation of Trypanosoma cruzi infection in immunosuppressed patients: Contributions for the laboratorial diagnosis standardization». Revista Do Instituto De Medicina Tropical De Sao Paulo, 50, 65-66.

[9] BRENIERE S.F., VILLACIS A. eta AZNAR C. 2017. «Vector transmission: how it works, what transmits, where it occurs». American Trypanosomiasis Chagas Disease: One Hundred Years of Research, 2nd Edition, 497-515.

[10] LARANJA F.S., DIAS E., NOBREGA G. eta MIRANDA A. 1956. «Chagas' disease; a clinical, epidemiologic, and pathologic study». Circulation, 14, 1035-1060.

[11] CARLIER Y., SOSA-ESTANI S., LUQUETTI A.O. eta BUEKENS P. 2015. «Congenital Chagas disease: an update». Memorias Do Instituto Oswaldo Cruz, 110, 363-386. 
Chagasen gaixotasuna Europan, endemikoa ez izan arren kontuan hartzekoa

[12] OLIVEIRA I., TORRICO F., MUÑOZ J. eta GASCON J. 2010. «Congenital transmission of Chagas disease: a clinical approach». Expert Review of AntiInfective Therapy, 8, 945-956.

[13] SCHMUNIS G.A. 1999. «Prevention of transfusional Trypanosoma cruzi infection in Latin America». Memorias Do Instituto Oswaldo Cruz, 94, 93101.

[14] BERN C., MONTGOMERY S.P., KATZ L., CAGLIOTI S. eta STRAMER S.L. 2008. "Chagas disease and the US blood supply». Current Opinion in Infectious Diseases, 21, 476-482.

[15] MARTIN-DAVILA P., FORUN J., LOPEZ-VELEZ R., NORMAN F., DE OCA M.M., ZAMARRON P. et al. 2008. «Transmission of tropical and geographically restricted infections during solid-organ transplantation». Clinical Microbiology Reviews, 21, 60-96.

[16] PEREIRA K.S., SCHMIDT F.L., GUARALDO A.M.A., FRANCO R.M.B., DIAS V.L. eta PASSOS L.A.C. 2009. «Chagas' Disease as a Foodborne Illness». Journal of Food Protection, 72, 441-446.

[17] BRENIERE S.F., WALECKX E. eta AZNAR C. 2017. «Other forms of transmission: blood transfusion, organ transplantation, laboratory accidents, oral and sexual transmission». American Trypanosomiasis Chagas Disease: One Hundred Years of Research, 2nd Edition, 561-578.

[18] PIZZI T., NIEDMANN G. eta JARPA A. 1963. «Report of 3 cases of acute Chagas' disease produced by accidental laboratory infections». Boletín chileno de parasitología, 18, 32-36.

[19] COUDERT J., DESPEIGNES J., BATTESTI M.R. eta MICHEL-BRUN J. 1964. «A case of Chagas' disease caused by accidental laboratory contamination by T. cruzi». Bulletin de la Societe de pathologie exotique et de ses filiales, 57, 208-213.

[20] HOFFLIN J.M., SADLER R.H., ARAUKO F.G., PAGE W.E. eta REMINGTON J.S. 1987. «Laboratory-acquired Chagas disease». Transactions of the Royal Society of Tropical Medicine and Hygiene, 81, 437-440.

[21] HERWALDT B.L. 2001. «Laboratory-acquired parasitic infections from accidental exposures». Clinical Microbiology Reviews, 14, 659-688.

[22] GASCON J., BERN C. eta PINAZO M.J. 2010. «Chagas disease in Spain, the United States and other non-endemic countries». Acta Tropica, 115, 22-27.

[23] SCHMUNIS G.A. 2007. «The globalization of Chagas disease». ISBT Science Series, Volume 2, Issue 1, 2, 6-11.

[24] 2014ko EAEko Etorkin Atzerritarrei buruzko Inkestaren emaitzen txostena (EABI 2014) [Internet]. Osalan (Eusko Jaurlaritza). 2015 [2018ko azaroaren 18an kontsultatua]. Eskuragarri: http://www.osalan.euskadi.eus/contenidos/ documentacion/informe_epie_2014/eu_epds2012/adjuntos/2014ko_EABIren_txostena-eu.pdf

[25] Encuesta sobre inmigración en Navarra 2008 [Internet]. Nafarroako Gobernua. 2009 [2018ko azaroaren 18an kontsultatua]. Eskuragarri: http:// 
www .navarra.es/NR/rdonlyres/CA7C7E3F-BC58-444A-B69A-8CF482E1D311/142799/encuesta_inmigracion_2008.pdf

[26] NAT1 - Population par sexe, âge et nationalité en 2015 - Département des Pyrénées-Atlantiques (64) - Étrangers - Immigrés en 2015 [Internet]. Insee (Frantziako Gobernua). 2018 [2018ko azaroaren 18an kontsultatua]. Eskuragarri: https://www.insee.fr/fr/statistiques/3569322? sommaire=3569330\&geo =DEP-64

[27] BASILE L., JANSA J.M., CARLIER Y., SALAMANCA D.D., ANGHEBEN A., BARTOLONI A. et al. 2011. "Chagas disease in European countries: the challenge of a surveillance system». Eurosurveillance, 16, 14-23.

[28] JACKSON Y., ANGHEBEN A., CARRILERO FERNANDEZ B., JANSA I LOPEZ DEL VALLADO J.M., JANNIN J.G. eta ALBAJAR-VIÑAS P. 2009. «Management of Chagas disease in Europe. Experiences and challenges in Spain, Switzerland and Italy». Bulletin de la Societe de pathologie exotique, 102, 326-329.

[29] MONGE-MAILLO B. eta LOPEZ-VELEZ R. 2017. "Challenges in the management of Chagas disease in Latin-American migrants in Europe». Clinical Microbiology and Infection, 23, 290-295.

[30] REQUENA-MENDEZ A., ALDASORO E., DE LAZZARI E., SICURI E., BROWN M., MOORE D.A.J. et al. 2015. «Prevalence of Chagas Disease in Latin-American Migrants Living in Europe: A Systematic Review and Metaanalysis». PLoS Neglected Tropical Diseases, 9.

[31] REQUENA-MENDEZ A., ALBAJAR-VIÑAS P., ANGHEBEN A., CHIODINI P., GASCON J., MUÑOZ J. et al. 2014. «Health Policies to Control Chagas Disease Transmission in European Countries». PLoS Neglected Tropical Diseases, 8.

[32] ANTINORI S., GALIMBERTI L., BIANCO R., GRANDE R., GALLI M. eta CORBELLINO M. 2017. «Chagas disease in Europe: A review for the internist in the globalized world». European Journal of Internal Medicine, 43, 6-15.

[33] FLORES-CHAVEZ M.D., MERINO F.J., GARCIA-BUJALANCE S., MARTIN-RABADAN P., MERINO P., GARCIA-BERMEJO I. et al. 2011. «Surveillance of Chagas disease in pregnant women in Madrid, Spain, from 2008 to 2010». Eurosurveillance, 16, 22-28.

[34] NAVARRO M., NAVAZA B., GUIONNET A. eta LOPEZ-VELEZ R. 2012. «Chagas Disease in Spain: Need for Further Public Health Measures». PLoS Neglected Tropical Diseases, $\mathbf{6}, 4$.

[35] TORRICO F., ALONSO-VEGA C., SUAREZ E., RODRIGUEZ P., TORRICO M.C., DRAMAIX M. et al. 2005. «Endemic level of infection by Trypanosoma cruzi in the mother's place of residence and development of congenital Chagas disease in Bolivia». Revista Da Sociedade Brasileira De Medicina Tropical, 38, 17-20.

[36] MURCIA L., CARRILERO B., MUÑOZ-DAVILA M.J., THOMAS M.C., LOPEZ M.C. eta SEGOVIA M. 2013. «Risk Factors and Primary Preven- 
tion of Congenital Chagas Disease in a Nonendemic Country». Clinical Infectious Diseases, 56, 496-502.

[37] BASILE L., OLIVEIRA I., CIRUELA P., PLASENCIA A. eta WORKING GROUP FOR DEVELOPING THE CATALONIAN SCREENING PROGRAMME FOR CONGENITAL TRANSMISSION OF CHAGAS DISEASE. 2011. «The current screening programme for congenital transmission of Chagas disease in Catalonia, Spain». Eurosurveillance, 16, 16-21.

[38] MORA M.C., NEGRETTE O.S., MARCO D., BARRIO A., CIACCIO M., SEGURA M.A. et al. 2005. «Early diagnosis of congenital Trypanosoma cruzi infection using PCR, hemoculture, and capillary concentration, as compared with delayed serology». Journal of Parasitology, 91, 1468-1473.

[39] BENJAMIN R.J., STRAMER S.L., LEIBY D.A., DODD R.Y., FEARON M. eta CASTRO E. 2012. «Trypanosoma cruzi infection in North America and Spain: evidence in support of transfusion transmission (CME)». Transfusion, 52, 1913-1921.

[40] KITCHEN A.D., HEWITT P.E. eta CHIODINI P.L. 2012. «The early implementation of Trypanosoma cruzi antibody screening of donors and donations within England: preempting a problem». Transfusion, 52, 1931-1939.

[41] NIEDERHAUSER C., GOTTSCHALK J. eta TINGUELY C. 2016. «Selective Testing of At-Risk Blood Donors for Trypanosoma cruzi and Plasmodium spp. in Switzerland». Transfusion Medicine and Hemotherapy, 43, 169-176.

[42] BLUMENTAL S., LAMBERMONT M., HEIJMANS C., RODENBACH M.P., EL KENZ H., SONDAG D. et al. 2015. «First Documented Transmission of Trypanosoma cruzi Infection through Blood Transfusion in a Child with Sickle-Cell Disease in Belgium». PLoS Neglected Tropical Diseases, $9,8$.

[43] PIRON M., VERGES M., MUÑOZ J., CASAMITJANA N., SANZ S., MAYMO R.M. et al. 2008. «Seroprevalence of Trypanosoma cruzi infection in at-risk blood donors in Catalonia (Spain)». Transfusion, 48, 1862-1868.

[44] Promoción de la donación de sangre II-Criterios básicos para la selección de donantes de sangre y componentes [Internet]. Osasun Ministerioa (Espainiako Gobernua). 2006 [2018ko azaroaren 20an kontsultatua]. Eskuragarri: https://www.mscbs.gob.es/profesionales/saludPublica/medicina Transfusional/publicaciones/docs/criteriosBasicosTomoII_2006_030907. pdf

[45] CANCINO-FAURE B., FISA R., RIERA C., GIRONA-LLOBERA E. eta JIMENEZ-MARCO T. 2016. «Where do Trypanosoma cruzi go? The distribution of parasites in blood components from fractionated infected whole blood». Transfusion, 56, 2233-2238.

[46] PINAZO M.J., MIRANDA B., RODRIGUEZ-VILLAR C., ALTCLAS J., SERRA M.B., GARCIA-OTERO E.C. et al. 2011. «Recommendations for management of Chagas disease in organ and hematopoietic tissue transplantation programs in nonendemic areas». Transplantation Reviews, 25, 91-101. 
[47] PEREZ-MOLINA J.A., PEREZ A.M., NORMAN F.F., MONGE-MAILLO B. eta LOPEZ-VELEZ R. 2015. "Old and new challenges in Chagas disease». Lancet Infectious Diseases, 15, 1347-1356.

[48] BRISSEAU J.M., CEBRON J.P., PETIT T., MARJOLET M., CUILLIERE P., GODIN J. et al. 1988. «Chagas myocarditis imported into France». Lancet, 1, 1046.

[49] VILLALBA R., FORNES G., ALVAREZ M.A., ROMAN J., RUBIO V., FERNANDEZ M. et al. 1992. «Acute Chagas disease in a recipient of a bone-marrow transplant in Spain - Case report». Clinical Infectious Diseases, 14, 594-595.

[50] RIERA C., GUARRO A., EL KASSAB H., JORBA J.M., CASTRO M., ANGRILL R. et al. 2006. "Congenital transmission of Trypanosoma cruzi in Europe (Spain): A case report». American Journal of Tropical Medicine and Hygiene, 75, 1078-1081.

[51] FLORES-CHAVEZ M., FAEZ Y., OLALLA J.M., CRUZ I., GARATE T., RODRIGUEZ M. et al. 2008. «Fatal congenital Chagas' disease in a non-endemic area: a case report». Cases journal, 1, 302.

[52] MUÑOZ J., PRAT J.G.I., GALLEGO M., GIMENO F., TREVINO B., LOPEZ-CHEJADE P. et al. 2009. «Clinical profile of Trypanosoma cruzi infection in a non-endemic setting: Immigration and Chagas disease in Barcelona (Spain)». Acta Tropica, 111, 51-55.

[53] GOBBI F., ANGHEBEN A., ANSELMI M., POSTIGLIONE C., REPETTO E., BUONFRATE D. et al. 2014. «Profile of Trypanosoma cruzi Infection in a Tropical Medicine Reference Center, Northern Italy». PLoS Neglected Tropical Diseases, $8,6$.

[54] REPETTO E.C., ZACHARIAH R., KUMAR A., ANGHEBEN A., GOBBI F., ANSELMI M. et al. 2015. «Neglect of a Neglected Disease in Italy: The Challenge of Access-to-Care for Chagas Disease in Bergamo Area». PLoS Neglected Tropical Diseases, 9, 13.

[55] SANCHEZ-MONTALVA A., SALVADOR F., RODRIGUEZ-PALOMARES J., SULLEIRO E., SAO-AVILES A., ROURE S. et al. 2016. «Chagas Cardiomyopathy: Usefulness of EKG and Echocardiogram in a Non-Endemic Country». PLoS One, 11, 13.

[56] GARCIA-ALVAREZ A., SITGES M., PINAZO M.J., REGUEIROCUEVA A., POSADA E., POYATOS S. et al. 2010. «Chagas Cardiomiopathy: The Potential of Diastolic Dysfunction and Brain Natriuretic Peptide in the Early Identification of Cardiac Damage». PLoS Neglected Tropical Diseases, $4,8$.

[57] PEREZ-AYALA A., PEREZ-MOLINA J.A., NORMAN F., MONGEMAILLO B., FARO M.V. eta LOPEZ-VELEZ R. 2011. «Gastro-intestinal Chagas disease in migrants to Spain: prevalence and methods for early diagnosis». Annals of Tropical Medicine and Parasitology, 105, 25-29.

[58] PINAZO M.J., LACIMA G., ELIZALDE J.I., POSADA E.J., GIMENO F., ALDASORO E. et al. 2014. «Characterization of Digestive Involvement 
Chagasen gaixotasuna Europan, endemikoa ez izan arren kontuan hartzekoa

in Patients with Chronic T. cruzi Infection in Barcelona, Spain». PLoS Neglected Tropical Diseases, $8,7$.

[59] BRENER Z. 1971. «Life cycle of Trypanosoma cruzi». Revista do Instituto de Medicina Tropical de Sao Paulo, 13, 171-178.

[60] TYLER K.M. eta ENGMAN D.M. 2001. «The life cycle of Trypanosoma cruzi revisited». International Journal for Parasitology, 31, 472-481.

[61] CDC - Chagas Disease - Biology [Internet]. Centers for Disease Control and Prevention. 2015 [2019ko martxoaren 19an kontsultatua]. Eskuragarri: https://www .cdc.gov/parasites/chagas/biology.html

[62] BERMUDEZ J., DAVIES C., SIMONAZZI A., REAL J.P. eta PALMA S. 2016. «Current drug therapy and pharmaceutical challenges for Chagas disease». Acta Tropica, 156, 1-16.

[63] MINISTÉRIO DA SAÚDE. SECRETARIA DE VIGILÂNCIA EM SAÚDE. 2005. «Brazilian Consensus on Chagas disease». Revista da Sociedade Brasileira de Medicina Tropical, 38, 7-29.

[64] BERN C., MONTGOMERY S.P., HERWALDT B.L., RASSI A. JR., MARIN-NETO J.A., DANTAS R.O. et al. 2007. «Evaluation and treatment of Chagas disease in the United States - A systematic review». Journal of the American Medical Association, 298, 2171-2181.

[65] GRUNBERG E., BESKID G., CLEELAND R., DELORENZO W.F., TITSWORTH E., SCHOLER H.J. et al. 1967. «Antiprotozoan and antibacterial activity of 2-nitroimidazole derivatives». Antimicrobial agents and chemotherapy, 7, 513-519.

[66] PEREZ-MOLINA J.A., NORMAN F. eta LOPEZ-VELEZ R. 2012. «Chagas Disease in Non-Endemic Countries: Epidemiology, Clinical Presentation and Treatment». Current Infectious Disease Reports, 14, 263-274.

[67] URBINA J.A. 2010. «Specific chemotherapy of Chagas disease: Relevance, current limitations and new approaches». Acta Tropica, 115, 55-68.

[68] COURA J.R. eta DE CASTRO S.L. 2002. «A critical review on Chagas disease chemotherapy». Memorias Do Instituto Oswaldo Cruz, 97, 3-24.

[69] BERN C. 2011. «Antitrypanosomal Therapy for Chronic Chagas' Disease». New England Journal of Medicine, 364, 2527-2534.

[70] BONNEY K.M. eta ENGMAN D.M. 2015. «Autoimmune Pathogenesis of Chagas Heart Disease Looking Back, Looking Ahead». American Journal of Pathology, 185, 1537-1547.

[71] GUTIERREZ F.R.S., GUEDES P.M.M., GAZZINELLI R.T. eta SILVA J.S. 2009. «The role of parasite persistence in pathogenesis of Chagas heart disease». Parasite Immunology, 31, 673-685.

[72] KUSCHNIR E., SGAMMINI H., CASTRO R., EVEQUOZ C., LEDESMA R. eta BRUNETTO J. 1985. «Evaluation of cardiac function by radioisotopic angiography, in patients with chronic Chagas cardiopathy». Arquivos brasileiros de cardiología, 45, 249-256.

[73] DIAS J.C.P., RAMOS A.N., GONTIJO E.D., LUQUETTI A., SHIKANAIYASUDA M.A., COURA J.R. et al. 2016. «2nd Brazilian Consensus on 
Chagas Disease, 2015». Revista Da Sociedade Brasileira De Medicina Tropical, 49, 59.

[74] DE ANDRADE J.P., NETO J.A.M., DE PAOLA A.A.V., VILAS-BOAS F., OLIVEIRA G.M.M., BACAL F. et al. 2011. «I Latin American Guidelines for the Diagnosis and Treatment of Chagas' Heart Disease. Executive Summary». Arquivos Brasileiros De Cardiologia, 96, 9.

[75] ACQUATELLA H. 2007. «Echocardiography in Chagas heart disease». Circulation, 115, 1124-1131.

[76] HUNT S.A., ABRAHAM W.T., CHIN M.H., FELDMAN A.M., FRANCIS G.S., GANIATS T.G. et al. 2005. "ACC/AHA 2005 Guideline Update for the Diagnosis and Management of Chronic Heart Failure in the Adult». Circulation, 112, e154-235.

[77] QUIROS F.R., MORILLO C.A., CASAS J.P., CUBILLOS L.A. eta SILVA F.A. 2006. «CHARITY: Chagas cardiomyopathy bisoprolol intervention study: a randomized double-blind placebo force-titration controlled study with Bisoprolol in patients with chronic heart failure secondary to Chagas cardiomyopathy [NCT00323973]». Trials, 7, 11.

[78] BOCCHI E.A. eta FIORELLI A. 2001. «The paradox of survival results after heart transplantation for cardiomyopathy caused by Trypanosoma cruzi. First Guidelines Group for Heart Transplantation of the Brazilian Society of Cardiology». Annals of Thoracic Surgery, 71, 1833-1838.

[79] HERBELLA F.A.M., AQUINO J.L.B., STEFANI-NAKANO S., ARTIFON E.L.A., SAKAI P., CREMA E. et al. 2008. «Treatment of achalasia: lessons learned with Chagas' disease». Diseases of the Esophagus, 21, 461-467. 